International Journal of Agriculture, Environment and Bioresearch

Vol. 06, No. 05; 2021

ISSN: $2456-8643$

\title{
DETERMINATIONS OF THRESHOLDS AND ALERT LEVELS RELATING TO THE RISK OF STRONG WIND IN BENIN
}

\author{
KOUMASSI Degla Herve \\ Pierre Pagney Laboratory ' Climate, Water, Ecosystems and Development '(LACEEDE / UAC), BP: 922, \\ University of Abomey-calavi, Benin; Tel: (00229) 95373824 \\ https://doi.org/10.35410/IJAEB.2021.5660
}

\begin{abstract}
There will be more extreme climatic phenomena in the years to come because of warming, in fact, each year several extreme climatic phenomena affect the planet. they are more and more violent. This research aims to determine the thresholds and alert levels for strong winds in Benin

Wind data and meteorological phenomena observations extracted from different sources on the Cotonou (1981-2016) and Parakou (1981-2015) and Kandi (1970-1987) stations and the economic and socio - anthropological data collected on different localities are used to establish the thresholds and alert levels relating to the risk of strong wind in Benin.

Over the periods considered, it appears that the strong winds, mainly from the sector, are linked to the passage of Meso-Scale Convective Systems (SCME) with speeds of up to $33 \mathrm{~m}$ : s-1 (118 $\mathrm{km}$ : h-1). They are often accompanied by moderate to heavy rainfall - thunderstorms. Their annual frequency is low (less than 1\%). The damage they cause includes ruffling buildings and destroying crops. Their classification was the subject of a vigilance table indicating the thresholds and alert levels selected. It locates extreme strong wind events leading to exceptional damage at a speed threshold greater than $23 \mathrm{~m}$ : s-1 (82 km: h-1) with return periods greater than 5 years. Below this threshold are the manifestations of strong wind causing damage with medium recurrence.
\end{abstract}

Keywords: Thresholds, levels, alert, risk, strong winds, Benin.

\section{INTRODUCTION}

The upsurge in natural disasters in general, and those linked to climatic hazards in particular, represents a major challenge for the world community today. The IPCC mentions that between the 3rd and the 4th report (2001-2007), the vulnerability of communities to climate risks increased all over the world. Among these extremes, storms are the deadliest events with more than 242000 deaths, which represents more than $40 \%$ of the global number of deaths caused by climatic phenomena, $89 \%$ of these deaths having taken place in low-income countries.

Storms are, in fact, violent meteorological phenomena on a synoptic scale, characterized by strong, rapid winds exceeding $90 \mathrm{~km} . \mathrm{h}-1$ and intense precipitation. In tropical environments and particularly in West Africa, the most recurring meteorological phenomena causing these strong winds are squall lines and more generally Mesoscale Convective Systems (SCME). These SCMEs, along with wave phenomena, constitute the major meteorological phenomena of the climate of West Africa (Landsea and Gray, 1992). In Benin in particular, the consequences 
linked to the passage of SCME and associated strong winds are numerous but little documented. These events mostly affect rural communities causing material damage and loss of life.

The prevention and management of these disasters has however become in recent years one of the major challenges for the societies most affected by these phenomena. In Benin, significant progress has been made in disaster management for the most disadvantaged populations. But in order to minimize the losses caused, prevention remains the most important process and early warning is one of its indispensable components. This research aims to determine the thresholds and alert levels of strong winds in Benin

Benin is a country in West Africa which is located in the tropical zone between the equator and the Tropic of Cancer. It is located between 6021 'and 12030' north latitude and between $1^{\circ}$ and $3^{\circ} 30$ 'east longitude (Figure 1). Benin covers an area of 114,763 km2. From north to south, it stretches for $700 \mathrm{~km}$; Its width varies from $125 \mathrm{~km}$ along the coast to $325 \mathrm{~km}$ at the Tanguiéta Ségbana latitude.

According to Boko et al. (2012), Benin's climate, tropical, hot and humid, has many seasonal and geographic nuances. A distinction is generally made between the southern region and the northern region. Influenced by the Atlantic Ocean, the southern region is characterized by a fourseason sub-equatorial climate (two rainy seasons and two dry seasons).

Closer to the Sahelian climate, the northern part of Benin is governed by the Sudanese climate in the northeast and Atacorian in the northwest with a single dry season and a single rainy season. However, there is a spatial disparity in southern Benin and northern Benin.

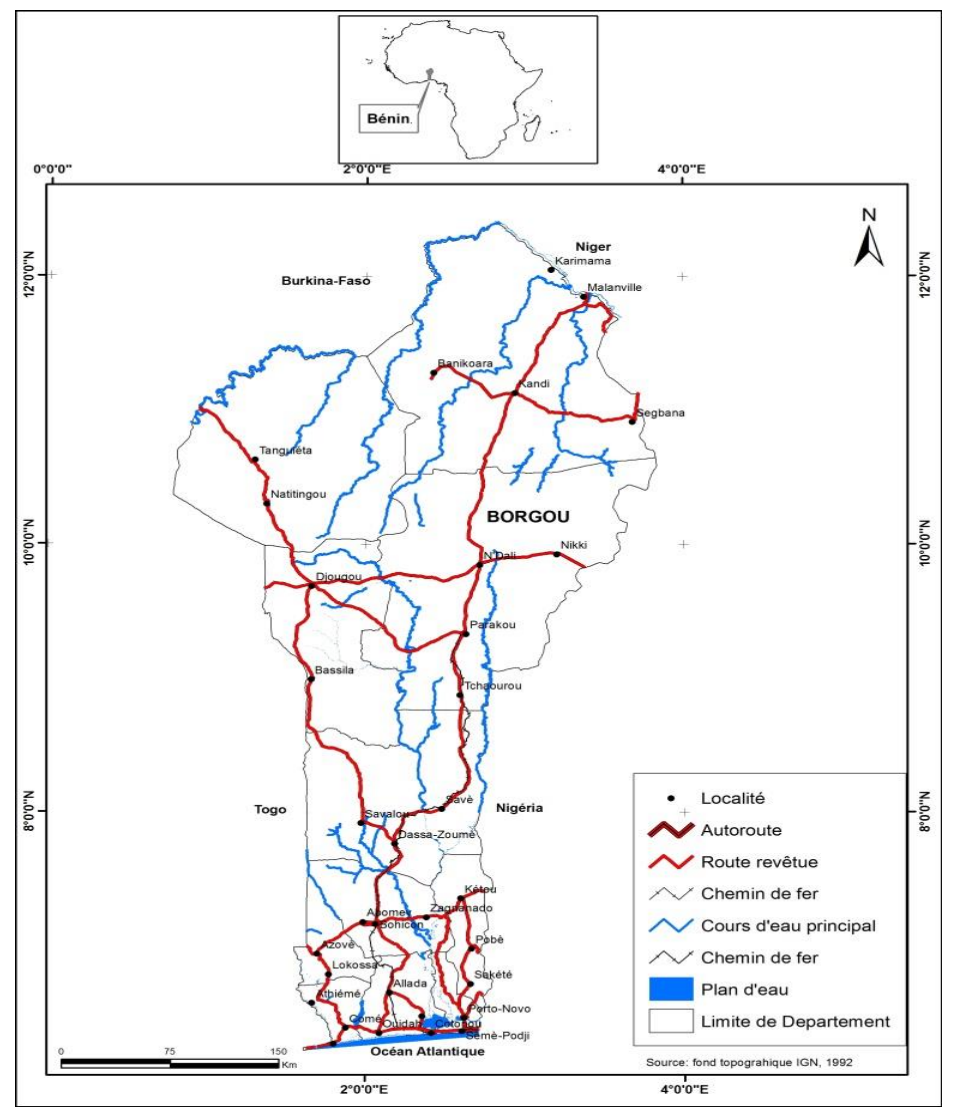


Vol. 06, No. 05; 2021

ISSN: $2456-8643$

\section{METHODOLOGICAL APPROACH}

\section{Data used}

\section{Wind data and meteorological phenomena data.}

Daily observations of instantaneous maximum wind available on the six (6) synoptic stations of the country. They were provided in handwritten form by the National Meteorological Agency. Statistics on data availability are presented in Table I.

Table I: Availability of data on the six synoptic stations

\begin{tabular}{|l|c|c|c|c|c|c|}
\hline Station & Cotonou & Bohicon & Savè & Parakou & Natitingou & Kandi \\
\hline & 35 ans & 2 ans & 5 ans & 34 ans & 5 ans & 18 ans \\
& $(1981-2016)$ & $(1978-1979)$ & $(1976-1980)$ & $(1981-2015)$ & $(1973-1977)$ & $(1970-1987)$ \\
\hline
\end{tabular}

From the analysis of Table VII, it emerges that only the stations of Cotonou, Parakou and to a lesser extent that of Kandi have instantaneous maximum wind data over relatively long periods, unlike those of Bohicon, Savè and Parakou, where the unavailability of maximum wind recorders has been observed over several years. It is therefore the first three (3) stations mentioned (Cotonou, Parakou and Kandi) which are retained within the framework of this study. Even if this number of stations turns out to be insufficient, their geographical location on the map of Benin allows us to take into account the different types of climate encountered in the country and to consider that, from a climatological point of view, the results of this work may be representative of the whole country.

Regular three-hourly wind observations from SYNOP messages sent by the various synoptic stations. These messages are compiled, decoded and processed by the National Centers for Environmental Information (NCEI) and the National Oceanic and Atmospheric Administration (NOAA).

Seasonal and interannual variability of surface winds

Because it is difficult to access small-scale processes over a long period of time using daily data, we first used the monthly and annual statistics of the various parameters to describe their evolution over time. seasonal and interannual scale. These statistics mainly concern the frequencies of occurrence of the different categories of strong winds.

The analysis of the wind regime led to consider the wind thresholds from speeds greater than or equal to $10 \mathrm{~ms}-1$, which results from the fact that speeds less than $10 \mathrm{~ms}-1$ are in the domain of the prevailing wind for the most part. stations. On the basis of this analysis, the variations in the frequency of occurrence of winds with speeds greater than $10 \mathrm{~ms}-1,15 \mathrm{~ms}-1,20 \mathrm{~ms}-1$ and $25 \mathrm{~ms}-1$ (noted in the rest of the text V10, V15, V20 and V25 respectively) were analyzed.

Finally, the frequency analysis of the instantaneous maximum wind data series and the hierarchical ascending classification $(\mathrm{CAH})$ of wind speeds will make it possible, on the one 
Vol. 06, No. 05; 2021

ISSN: $2456-8643$

hand, to determine the return periods of extreme wind events and on the other hand, to classify these winds on a scale of four (4) levels corresponding to the vigilance thresholds to be used to carry out the early warning.

\section{RESULTS}

\subsection{Frequency of instantaneous maximum winds}

The wind roses in Figure 2 show the direction, speed and frequency of the instantaneous maximum daily wind data on the 3 stations selected for the study.
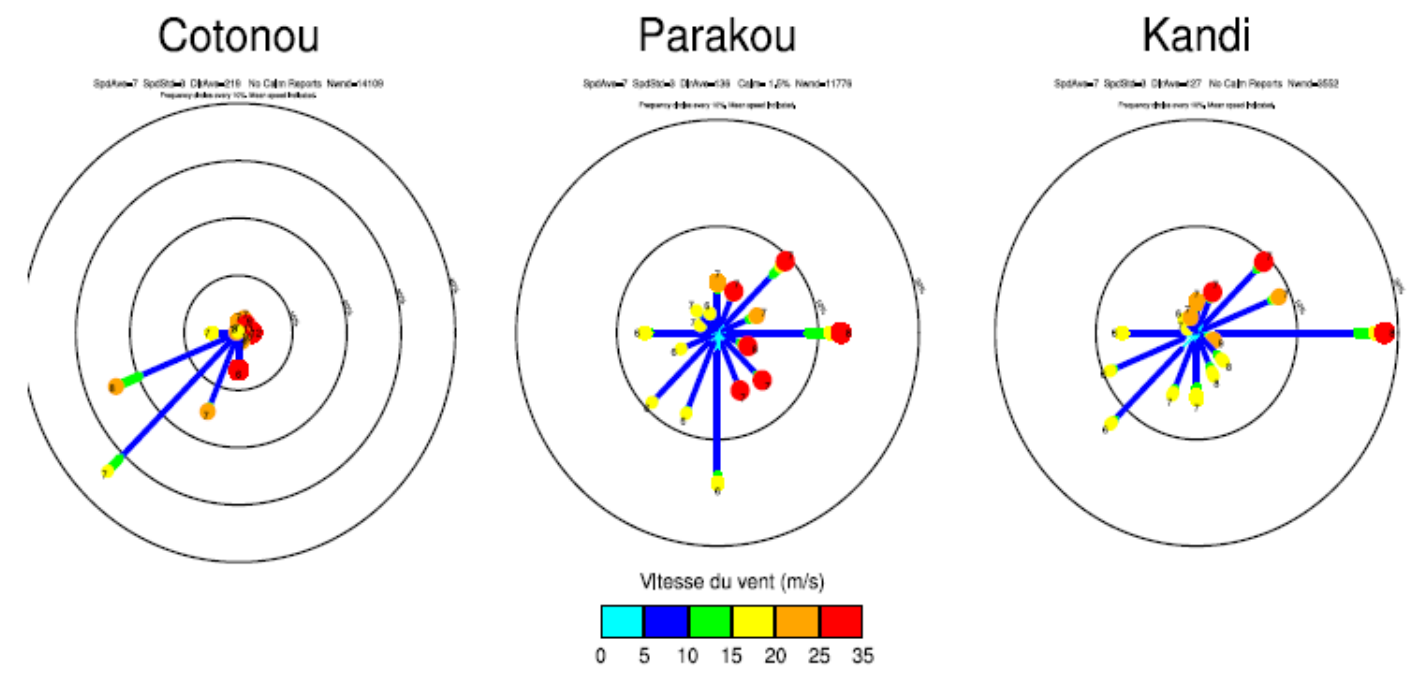

Figure 26: Roses of instantaneous maximum winds at Cotonou, Parakou and Kandi Source: Data processing

On all three stations, the direction of the maximum winds does not differ significantly from the direction of the average winds presented above in Figure 4

In Cotonou, Parakou and Kandi, the most frequent strong winds (more than 75\%) have speeds between 5 and $10 \mathrm{~m} . \mathrm{s}-1$. In Cotonou, these winds are mainly from the south-westerly sector and their speed can be close to the daily averages at certain times of the year, in particular during the months of July-August-September when the south-westerly flow experiences a clear acceleration. from the coast inland. In Parakou and Kandi, apart from the north-west sector, these speed values ( 5 to $10 \mathrm{~ms}-1)$ are reached almost everywhere and it would be a priori difficult to make a link with a precise meteorological factor: it is a question of a priori prevailing winds. Thus less than $25 \%$ of the instantaneous maximum wind speed values are greater than 10 m.s 1. It is interesting to note that on all 3 stations winds with speeds greater than $25 \mathrm{~m} . \mathrm{s}-1$ come from the northeast, east or southeast and are the least frequent. The occurrence of these winds should be linked to the dynamics of SCMEs which circulate from east to west in the tropical zone, preceded most of the time by strong easterly winds outside the gusts, these SCMEs also generate meteorological phenomena. generally quantified in the messages of regular and special 
observations: in our regions these phenomena are often limited to squalls, thunderstorms, showers and moderate to heavy precipitation (rain, hail). The forecast and warning of strong winds therefore depends essentially on the forecast of the meteorological factors that generate them. In view of the distribution of maximum winds thus presented, it becomes clear that the most extreme winds originate from SCME.

\subsection{Variability of winds and meteorological phenomena}

To better identify the origin or the meteorological factors linked to the occurrence of strong winds on the 3 stations concerned, we propose to study the occurrence of instantaneous maximum winds. This makes it possible to better understand the strong wind thresholds that could accompany extreme phenomena and consequently, to be able to carry out an effective early warning. Table III presents the estimate of the recurrence of the speed of strong winds and the associated return periods on the synoptic stations of Cotonou and Parakou. The time period covered by the Kandi station series does not allow the latter to be taken into account in this treatment which requires long series.

Table 2: Periods of return of strong wind speeds with confidence intervals in Cotonou and Parakou

\begin{tabular}{|l|c|c|c|c|c|c|}
\hline Stations & 2.0 ans & 5.0 ans & 10.0 ans & 20.0 ans & 50 ans & 100 ans \\
\hline Cotonou & 21 & 24 & 26 & 28 & 20 & 31 \\
& {$[20-22]$} & {$[23-26]$} & {$[24-28]$} & {$[25-30]$} & {$[26-33]$} & {$[27-35]$} \\
\hline Parakou & 21 & 26 & 29 & 32 & 35 & 38 \\
& {$[19-22]$} & {$[23-28]$} & {$[25-32]$} & {$[28-35]$} & {$[31-40]$} & {$[33-44]$} \\
\hline
\end{tabular}

Table 2 presents the estimate of the recurrence of the speed of strong winds and the associated return periods on the synoptic stations of Cotonou and Parakou. From the analysis, it emerges that recurring wind damage is caused by strong winds with a speed between 19 and $22 \mathrm{~m} / \mathrm{s}$, i.e. those with a probability of recurrence between $1 / 2$ and $1 / 5$ per year. Average recurrence wind damage, i.e. damage caused by strong winds with a recurrence probability between $1 / 10$ and $1 / 20$ per year, have a speed between 24 and $35 \mathrm{~m} / \mathrm{s}$. Further on, exceptional wind damage is caused by strong winds whose values are between 26 and $44 \mathrm{~m} / \mathrm{s}$, ie those whose probability of recurrence is between $1 / 50$ and 1/100 per year.

In view of these probabilities of occurrence thus reported, the speed records recorded in the history of the six synoptic stations in the country. Table IV presents the historical records for the six stations in Benin. 
Table 3: Speed records (in m.s - 1) recorded since the start of the observations in each station during the different months of the year.

\begin{tabular}{|l|l|l|l|l|l|l|l|l|l|l|l|l|l|}
\hline Station & Jan & Fev & Mar & Avr & Mai & Jui & Juil & Aoüt & Sept & Oct & Nov & Dec & $\begin{array}{l}\text { Date du record } \\
\text { absolu }\end{array}$ \\
\hline Kandi & 15 & 20 & 30 & 30 & 30 & 35 & 25 & 35 & 28 & 25 & 15 & 17 & 27 Aoüt 1951 \\
\hline Natitingou & 10 & 12 & 19 & 23 & 21 & 24 & 23 & 15 & 22 & 24 & 20 & 10 & - \\
\hline Parakou & 20 & 23 & 23 & 26 & 45 & 29 & 26 & 29 & 33 & 23 & 23 & 17 & 3 Mai 1979 \\
\hline Save & 15 & 19 & 28 & 28 & 20 & 21 & 19 & 10 & 20 & 19 & 15 & 14 & - \\
\hline Bohicon & 14 & 20 & 36 & 20 & 10 & 17 & 14 & 14 & 17 & 22 & 15 & 16 & 17 Mars 1959 \\
\hline Cotonou & 26 & 34 & 51 & 38 & 33 & 32 & 22 & 23 & 21 & 29 & 28 & 18 & 8 Mars 1962 \\
\hline
\end{tabular}

Source: METEO BENIN

From the analysis it emerges that although they are more frequent at the beginning of the season, the strong winds which can cause damage with average or exceptional recurrence can occur at any time during the rainy season and sometimes during the dry season if some meteorological conditions are met (monsoon call due to the presence of an extra tropical thalweg for example). In addition, based on the probabilities reported in Table XIV, we can see that these absolute records have return periods of more than 20 years except in Natitingou where the wind records seem weaker. The mountainous terrain of Natitingou could therefore help to slow down or deflect the strong winds that affect the region. Finally, the speed record recorded in Cotonou appears to be an event of rare exceptionality in that its return period is over 100 years.

\subsection{Classification of strong winds on a scale of four levels: the vigilance table}

Based on their frequency and direction, strong winds are classified into four (4) groups representing the scale of four (4) alert levels. Each of these levels is associated with a color (green, yellow, orange or red), the characteristics of the winds included and a description of the probable damage that these winds could cause. Table 4 .shows the different alert levels retained for the classification of strong winds in Benin as well as the socio-economic damage potentially associated with their occurrence.

Table 4: Vigilance threshold selected for the early warning of strong winds in Benin

\begin{tabular}{|c|c|c|c|c|}
\hline Alert level & $\begin{array}{c}\text { Instantaneous } \\
\text { maximum } \\
\text { speed }\end{array}$ & Characteristics & Probable damage & Vigilance \\
\hline
\end{tabular}


Vol. 06, No. 05; 2021

ISSN: $2456-8643$

\begin{tabular}{|c|c|c|c|}
\hline $\begin{array}{l}<8 \mathrm{~m} / \mathrm{s} \\
<28 \mathrm{~km} / \mathrm{h}]\end{array}$ & $\begin{array}{l}\text { Prevailing winds, } \\
\text { therefore very frequent } \\
\text { all year round by } \\
\text { clear or cloudy, stable or } \\
\text { unstable. }\end{array}$ & No particular damage. & $\begin{array}{l}\text { No particular } \\
\text { vigilance. }\end{array}$ \\
\hline $\begin{array}{l}<8 \text { à } 12 \mathrm{~m} / \mathrm{s} \\
<28 \text { à } 43 \mathrm{~km} / \mathrm{h}\end{array}$ & $\begin{array}{l}\text { Prevailing winds, } \\
\text { therefore very frequent } \\
\text { all year round by } \\
\text { clear or cloudy weather } \\
\text { stable or unstable. }\end{array}$ & No particular damage. & $\begin{array}{l}\text { No particular } \\
\text { vigilance. }\end{array}$ \\
\hline $\begin{array}{l}12 \text { à } 23 \text { m/s } \\
43 \text { à } 82 \text { km/h }\end{array}$ & $\begin{array}{l}\text { Strong gales, easterly on } \\
\text { average, accompanying } \\
\text { SCME, frequent at the } \\
\text { beginning and in the } \\
\text { middle of the rainy } \\
\text { season, in unstable } \\
\text { cloudy weather, with } \\
\text { moderate to heavy } \\
\text { precipitation. }\end{array}$ & $\begin{array}{l}\text { Power cuts and } \\
\text { phone may eject } \\
\text { networks, roofs may be } \\
\text { damaged, tree branches } \\
\text { may break, road traffic } \\
\text { may be disrupted. }\end{array}$ & $\begin{array}{l}\text { Be very } \\
\text { vigilant, } \\
\text { strong winds } \\
\text { are provided }\end{array}$ \\
\hline $\begin{array}{l}>23 \mathrm{~m} / \mathrm{s} \\
>82 \mathrm{~km} / \mathrm{h}\end{array}$ & $\begin{array}{l}\text { Strong winds, east } \\
\text { direction on average, } \\
\text { accompanying SCME } \\
\text { (squall lines or cloudy } \\
\text { clusters), little frequent, } \\
\text { non-seasonal, under } \\
\text { heavy precipitation. }\end{array}$ & $\begin{array}{l}\text { Electricity and } \\
\text { telephone cuts can } \\
\text { affect the networks, } \\
\text { significant damage can } \\
\text { be expected on homes } \\
\text { and plantations, road } \\
\text { traffic can be very } \\
\text { difficult, air transport, } \\
\text { rail and sea can be } \\
\text { seriously affected, } \\
\text { significant flooding is } \\
\text { to be feared. }\end{array}$ & $\begin{array}{l}\text { Absolute } \\
\text { vigilance is } \\
\text { required, } \\
\text { winds } \\
\text { of } \\
\text { exceptional } \\
\text { intensity are } \\
\text { planned. }\end{array}$ \\
\hline
\end{tabular}

Sources: Data processing, 
Vol. 06, No. 05; 2021

ISSN: $2456-8643$

\section{CONCLUSION}

The meteorological situations that generate strong winds over Benin are primarily linked to the passage of SCMEs, in particular squall lines and stormy cloud clusters. These winds are mostly easterly and may be followed by moderate to heavy rain - thunderstorms. The study shows that the annual frequency of these strong winds is relatively low (less than $1 \%$ on average). Their manifestation is much more frequent at the beginning and in the middle of the rainy season. The simultaneous reading of the results from the frequency analysis and the ACH shows that:

-Winds whose instantaneous maximum speeds are less than $19 \mathrm{~m} . \mathrm{s}-1(68 \mathrm{~km} . \mathrm{h}-1)$ have a high probability of annual occurrence, their return period is less than 2 years. They correspond to the worst of situations with orange vigilance.

- Red vigilance involves winds whose instantaneous maximum speeds are greater than 23 m.s $1(82 \mathrm{~km} . \mathrm{h}-1)$ with return periods greater than or equal to 5 years. These winds can cause damage with moderate or exceptional recurrence.

The vigilance table resulting from this study becomes an essential tool for early warning of the risks associated with strong winds. This alert, to be effective, must combine a correct meteorological forecast of strong winds, and therefore of the activity of the SCMEs which are of interest to the localities, and an effective taking into account of the extent of the socio-economic situation of the populations of these localities. targets (environment, infrastructure, etc.). This forecast must be continuously updated to take into account the improvement or deterioration of the forecast meteorological phenomena, and therefore requires technical means for real-time monitoring of the situation, for example weather radar.

\section{REFERENCE}

Adedokun, J. A., W. O. Emofurieta, O. A. Adedeji, 1989: Physical, mine $\neg$ ralogical and chemical properties of Harmattan dust at Ile-Ife, Nigeria. Theoretical and AppliedClimatology, 40, 161169.

Boko M., F. Kosmowski, E. W. Vissin, 2012: The Challenges of Climate Change in Benin. Konrad - Adenauer - Stiftung, 73 pp.

Bonnissent, J., 1989: Course in tropical meteorology. NHS Notes.

Dhonneur, G., 1985: Treatise on tropical meteorology: application to the specific case of West and Central Africa. Volume 1, National Meteorological Department, $151 \mathrm{pp}$.

DMN, 1990: Brief overview on the climate of Benin. Notes from the National Meteorological Department (DMN) of Benin.

Encyclopædia Britannica, inc 2007: The New Encyclopædia Britannica. EncyclopædiaBritannica, inc. Volume 1.

IPCC, 2007: Climate change. Summary report. 2007 Climate Change Report: Synthesis Report. IPCC, Geneva, Switzerland, 103 pp. 
Hastenrath, S., 1995: Climate Dynamics of the Tropics. Kluwer, 488 pp. Houze, R. A., Jr., 1993: Cloud Dynamics. Academic Press, San Diego, 573 pp.

Landsea, C. W., W. M. Gray, 1992: The strong association between western Sahelian monsoon rainfall and intense Atlantic hurricanes. J Climate, 5, 435-452.

McTainsh, G. H., P. H. Walker, 1982: Nature and distribution of Harmattan dust. Z. Geomorph. N.F., 26, 417-435.

METEO FRANCE, 2014: Breakfasts at Météo - France. Meteorological vigilance. Presse Me'te'o - France, 14 pp.

ICAO, 2006: Doc 9157 Part 1: Aerodrome Design Manual. Tracks. 3rd Edition, 86 pp.

UNDP, 2010: Human Development Report 2010. The True Wealth of Nations: Pathways to Human Development. Communications Development Incorporated, $260 \mathrm{p}$

J. BONNISSENT, 1989: Course in Tropical Meteorology

WMO, 2001: No. 306, International Code Manual Volume I.2,

Florent BEUCHER, Course and manuals $\mathrm{N}^{\circ}$ 19, Tropical Meteorology: from trade winds to cyclones, Volumes 1 and 2

UNISDR, United Nations, 2009, Terminology for Disaster Risk Reduction.

\section{Webographie}

1- http://www.unisdr.org/2015/docs/climatechange/COP21 WeatherDisastersReport 2015 FINAL.pdf

2- http://beninmondeinfos.com/index.php/benin/21-societe/4276-benin-une-tornade-fait-desblesseset-d-enormes-degats-materiels-a-sakete

3- https://www.lavoile.org/beaufort.htm

4- http://www.meteo.org/phenomen/vent.htm

5- http://vigilance.meteofrance.com/html/vigilance/guideVigilance/dm vent.html

6- https://www.ncdc.noaa.gov/isd

7- http://www.meteo45.com/dictionnaire meteo.html

8- https://fr.wikipedia.org/wiki/Système Concectif de méso-échelle

9- http://www.meteo45.com/lexique meteorologique.html 